\title{
Los trabajadores agrícolas temporales mexicanos en Canadá y la covid-19
}

\author{
Mexican temporary agricultural workers in Canada and covid-19
}

\author{
Rosa María Vanegas García* ISSN IMPRESO 1870-7599 | ISSN RED cóMPUTO 2448-7783 | 65-87 \\ Juan Manuel Sandoval Palacios** \\ RECIBIDO 24/11/20 | ACEPTADO 17/12/20
}

\begin{abstract}
Resumen. En 1947 comenzó la contratación de mano de obra agrícola extranjera temporal para trabajar en los campos provinciales de Canadá. En 1966 inició el Programa de Trabajadores Agrícolas Temporales con los países del Caribe de habla inglesa, en 1974 con México y, posteriormente, otras naciones centroamericanas. Actualmente, estos trabajadores forman parte de un emergente mercado laboral de América del Norte. Aquí se analiza la participación de mano de obra mexicana en dicho programa y la situación que se presentó con el brote epidémico de la covid-19, el cual se propagó de inmediato en todo el mundo. Se muestra que los trabajadores agrícolas tuvieron que presentarse a laborar en dichos campos, pues su actividad fue considerada esencial en el cultivo de los alimentos y una prioridad para la humanidad; en consecuencia, era fundamental que los gobiernos involucrados garantizaran los protocolos de salud y seguridad hacia los trabajadores agrícolas. Las medidas tomadas no fueron suficientes y los trabajadores fueron expuestos a contagios y fallecimientos. Inmediatamente, ambos gobiernos se comprometieron a reforzar la asistencia médica y a proteger los derechos laborales, cuestiones que los propios trabajadores han exigido desde hace ya varias décadas.
\end{abstract}

Palabras clave: dispositivo, discurso, saber/poder, ley, migración, migrante.

\begin{abstract}
In 1947 the Canadian agribusiness sector asked the government for foreign temporary agricultural labor. In 1966 the Seasonal Agricultural Workers Program (SAWP) was established between Canada and the Caribbean English speaking countries. In 1974 another Program was established with Mexico, and later on with other Central American countries. These workers are part of an emergent North American labor market. We analyze the participation of Mexican agricultural workers in such a program, and the situation created by the Pandemic of covid-19 of 2020 that was rapidly spreading all over the world. We show that Mexican agricultural workers had to labor in the Canadian farms because this activity was considered essential in food production and a priority for society. Consequently, it was fundamental that both governments commit themselves to follow the health and security protocols for the Mexican agricultural workers. The measures established by both governments were insufficient and the Mexican agricultural workers were exposed to the contagious disease and death. Immediately both governments committed themselves to strengthen medical assistance and to protect the labor rights of these workers, issues that had been part of the demands of such workers over several decades.
\end{abstract}

Keywords: instrument, discourse, knowledge/power, law, migration, migrant.

\footnotetext{
* Mexicana. Profesora investigadora de la Dirección de Etnología y Antropología Social del Instituto Nacional de Antropología e Historia. Correo-e: rosyvanegas@prodigy.net.mx

** Mexicano. Profesor investigador de la Dirección de Etnología y Antropología Social del Instituto Nacional de Antropología e Historia. Correo-e: juanmanuelsan.pal@gmail.com
} 


\section{Introducción}

A partir de la reestructuración del sistema capitalista mundial en las décadas de 1970 y 1980 (Kolko, 1988), y con la emergencia del capitalismo global, se reconfiguró el mapa económico de América del Norte y de otras regiones del mundo. En este proceso de reestructuración uno de los principales factores fue la movilidad del capital, gracias al desarrollo tecnológico (internet, satélites, etcétera) que impulsó la globalización de la producción y de las finanzas (Robinson, 2013; Sassen, 2001). Esa movilidad del capital, expresada por los grandes incrementos en inversión extranjera directa (IED) en los países subdesarrollados y en los altamente industrializados, ha creado también nuevas condiciones para la movilidad del trabajo (Overbeek, 2002; Sassen, 1988).

En la aludida reconfiguración del mapa económico, el capital transnacional ha impulsado la consolidación del mercado laboral regional de América del Norte (Estados Unidos, Canadá y México) como parte sustantiva del mercado laboral global (Sandoval, 2013; 2015; 2019). Si bien la migración de mexicanos a territorio estadounidense - que primero fue parte del septentrión novohispano, luego, en un breve periodo, parte de la nación mexicana y a partir de 1848 ya estaba integrado a la Unión Americana-, ha sido constante a través de corredores históricos de la migración (Acuña, 2007). De igual modo, aunque la migración actual comparte una cantidad de caracteres generales con las fases de migración anteriores, se basa en condiciones específicas que surgen de la reorganización de la economía mundial de las décadas de 1970 y 1980 (Sassen, 1988). Esta última comprende grandes flujos de fuerza laboral descalificada e inclusive semicalificada, en su mayoría de carácter irregular o indocumentado, cuyo empleo en muchas ocasiones se ha vuelto una condición para la existencia continua de pequeñas y medianas empresas (Overbeek, 202), hecho que diversos autores consideran clave para las grandes ganancias de los empleadores que obtienen una ventaja económica surgida de las diferencias de valor de la fuerza de trabajo en los respectivos países (Machuca, 1990). Concerniente a otros casos, el capital estadounidense ha generado un nuevo tipo de trabajador, el cual a lo largo de más de un siglo y medio de procesos migratorios entre ambas naciones se ha producido histórica y socialmente, con necesidades y capacidades particulares por su carácter de trabajador migrante y por las necesidades productivas que satisface esa fuerza de trabajo (Peña, 2013). En opinión de Peña (2013), este nuevo tipo de trabajador 
no es uno que pueda ser igualado al de México, que permanece estable, ni al de la Unión Americana; por el contrario, se trata de un trabajador específico con un valor de su fuerza de trabajo específico. Dicho valor es lo que determina la posibilidad de que su trabajo sea sometido a una mayor explotación, pues no existe un reconocimiento social (salarial) adecuado de las necesidades que precisa para que su reproducción sea suficiente; sin embargo, las consideraciones de Machuca y Peña no son excluyentes.

Además de las características mencionadas, la base para la conformación actual del mercado laboral regional de América del Norte es la temporalidad del trabajo migrante, misma que ha estado presente desde los albores del siglo XX, cuando en 1909 los entonces presidentes Porfirio Díaz, de México, y William H. Taft, de Estados Unidos, firmaron un convenio, mediante el cual mil trabajadores agrícolas de los estados del norte de México pudieran ser contratados para prestar sus servicios en los campos betabeleros de Colorado y Nebraska (Casarrubias, 2007); aunque Vargas y Campos (2007) aclaran que estos trabajadores fueron a los campos de remolacha azucarera del sur de California. Esta temporalidad fue clave en 1917, cuando el gobierno estadounidense entró de lleno en la Primera Guerra Mundial y fueron contratados alrededor de 72 mil mexicanos entre 1917 y 1918, derivado de la escasez de fuerza laboral y de una mayor demanda de la misma en la agricultura (Alanis, 1999; Durán, 2007).

Es natural que a partir de ambos antecedentes, en 1942, cuando Estados Unidos participó en la Segunda Guerra Mundial, volviera a requerir de dicha fuerza laboral en los sectores ferroviario - para el mantenimiento de vías férreas-y agrícola. En el Programa Bracero Ferroviario más de 100 mil contratados fueron a trabajar en el mantenimiento de las vías férreas de 1943 a 1945 (Driscoll, 1996). En el segundo, denominado Programa Mexicano Estadounidense de Prestación de Mano de Obra, mejor conocido como Programa Bracero (en realidad fueron varios los programas de Braceros) más de 5.5 millones de contratos se establecieron en un periodo de 22 años. A pesar de que los dos gobiernos iniciaron el programa, fue finalizado unilateralmente por el estadounidense en 1964 (Cohen, 2011). Éste, bajo la presión de los empresarios agrícolas, mantuvo un programa unilateral denominado H-2, manejado por el Departamento del Trabajo para que los empresarios pudieran contratar directamente a trabajadores agrícolas temporales. Poco después con la Ley de Reforma y Control de la Inmigración de 1986 (IRCA, 1986), el programa se dividió en H-2A (que se refiere a los servicios de mano de obra semicalificada) y H-2B (para el sector agrícola) (Trigueros, 2004). A partir de esa 
fecha, el programa se ha expandido en la última década del siglo XX y en las dos que van del siglo XXI en las diferentes iniciativas de ley para la regularización de los migrantes, el trabajo temporal se coloca en un punto central. ${ }^{1}$

El Programa Bracero también abrió las puertas a un porcentaje más de millones de trabajadores irregulares, aproximadamente la mitad de los cuales pudieron regularizarse a través de diversos mecanismos, en especial con la mencionada IRCA-1986, conocida como Ley Simpson-Rodino. Los flujos de dichos migrantes irregulares han ido en aumento durante varias décadas, hasta llegar aproximadamente a 6 millones que en la actualidad se suman a otros seis residentes legales (Sandoval, 2019).

En 1974 se estableció el Programa de Trabajadores Agrícolas Temporales (PTAT) entre Canadá y México, cuando se firmó un Memorándum de Entendimiento entre ambos países, basado en el Programa Bracero, en particular el Programa Bracero Ferroviario valorado como el «único ejemplo de un acuerdo binacional exitoso». En la presente investigación nos interesa mostrar el surgimiento y desarrollo del PTAT, y cómo la pandemia de la covid-19 impactó a las y los trabajadores agrícolas mexicanos temporales en Canadá en 2020.

\section{El Programa de Trabajadores Agrícolas Temporales Mexicanos en Canadá 1974-2020}

Pese a que este programa comenzó con unos cuantos cientos de trabajadores agrícolas mexicanos, a inicios de la década de 2000 la cifra de personas de origen

\footnotetext{
${ }^{1}$ La temporalidad del trabajo migratorio y este tipo de programas también se han vuelto clave para la gestión de las migraciones a escala global por parte de los gobiernos de los p aíses emisores y receptores, junto con las instancias globales como la Organización de las Naciones Unidas (ONU), el Banco Mundial (BM) y la Organización Internacional para las Migraciones (OIM), entre otras, que buscan impulsar las migraciones seguras, ordenadas y regulares, al establecer diversos mecanismos, como el del modelo filipino (cuyo Estado promueve la contratación, ahora mediante empresas privadas, de sus connacionales en todo el mundo) y otros más (ONU, 2018; Rodríguez, 2010; Sandoval, 2013; 2015). Para la inserción de los trabajadores migratorios en los mercados laborales regionales y de éstos en la integración del mercado mundial de fuerza laboral, el capital requiere de nuevas formas de control y regulación de los flujos migratorios. Al mismo tiempo, requiere de mecanismos de negociación que lleven a la integración y a la consolidación del mercado mundial de fuerza laboral. Para todo ello se estableció el Pacto Mundial por una Migración Segura, Ordenada y Regular aprobado el 10 de diciembre en Marrakech, Marruecos, por 160 países (ONU, 2018).
} 
campesino de diversas entidades contratadas para laborar en los campos agrícolas canadienses, donde la producción está altamente tecnificada y vinculada a los mercados mundiales (tabaco, hortalizas y frutales), había rebasado las $10 \mathrm{mil}$ personas debido a las necesidades de los capitales agroindustiales canadienses. Desde entonces, la cantidad fue en aumento en cada ciclo agrícola: en 2008 fueron aproximadamente 15 mil los contratados (Vanegas, 2008a), en 2012 ascendió a 17 mil 626; en 2013 a 18 mil 499; en 2014 a 19 mil 829; en 2015 a 20 mil, es decir, un aumento de sólo 171 trabajadores respecto del año anterior; no obstante, en 2016 subió a 23 mil 790 (19 por ciento); en 2017 incrementó a 25 mil 344; en 2018 a 26 mil; y en 2019 a 26 mil 399. ${ }^{2}$

Trabajadores agrícolas temporales de países centroamericanos se incorporaron al trabajo agrícola en los ranchos y granjas canadienses en la década de 2010. En 2005 Canadá y Guatemala establecieron un programa piloto con el propósito de llevar trabajadores agrícolas a los campos canadienses y posteriormente se incorporaron los salvadoreños. Esto no sólo se debió a los requerimientos de los capitales agroindustriales canadienses, sino también porque los trabajadores mexicanos comenzaron a buscar ayuda sindical para organizarse. Con el presidente Vicente Fox se acordó ampliar ese programa a distintos sectores, ya que el gobierno de Canadá requeriría de mano de obra calificada en el acondicionamiento y la operación de las instalaciones para los Juegos Olímpicos de Invierno de 2010 en Vancouver y Whistler. Ello sin considerar que se planteaba, de igual modo, impulsar programas de ese tipo para servicios de profesionistas, de la academia u otros sectores. Asimismo, Fox comenzó a negociar un Programa similar con España (Vanegas, 2008b), que si bien fue concretado por el gobierno del presidente Felipe Calderón para funcionar a partir de 2008, la crisis económica y financiera global que sumió a España en uno de los índices más altos de desempleo (más de 20 por ciento) de la Unión Europea, que en conjunto tenía la mitad de ese porcentaje, impidió que el programa fuera puesto en marcha.

Durante décadas, el flujo de trabajadores extranjeros hacia el país de la hoja de maple ha sido una constante para beneficiar a su economía. Desde 1947, cuando el sector agroindustrial solicitó mano de obra agrícola especializada extranjera temporal al gobierno de Canadá, éste lo propuso a gobiernos de los países del Caribe, que aceptaron la propuesta como prueba piloto en 1966. A raíz del éxito con los caribeños, el gobierno canadiense abrió sus puertas a otros países de Centroamérica 
y México, la oferta-demanda se ha extendido por más de 50 años en beneficio de la nación canadiense y, en particular, de los empresarios agrícolas.

Los gobiernos de los países involucrados de América Latina, y concretamente de México, en el Programa de Trabajadores Agrícolas Temporales (PTAT), donde miles de jornaleros extranjeros participan anualmente, se comprometen a firmar con Canadá un Memorándum de Entendimiento, donde se especifican los compromisos de cada uno de los que suscriben. En el memorándum se describe el contrato del PTAT, se pormenorizan las funciones del trabajador y el patrón en los campos agrícolas canadienses. Las tareas encomendadas a los trabajadores son arduas; y, entre los compromisos, se describe el derecho a la salud. En las granjas se prevé cualquier tipo de accidente, enfermedad o riesgo en la vida de los trabajadores, por lo que deben tener un seguro institucional de salud. Esta fuerza laboral temporal es explotada con todo y las puntualizaciones que se detallan en el contrato. En otros escritos hemos mostrado que las condiciones laborales y de vida de tales trabajadores son deplorables, incluso no cuentan con el apoyo de los consulados mexicanos (Sandoval y Vanegas, 2001; Vanegas, 2018).

En Canadá el Programa se ha distinguido por ser un modelo ideal de cooperación laboral temporal internacional, además ha demostrado supremacía al obtener mano de obra barata controlada, legal, segura y ordenada. Los empleadores están satisfechos del rendimiento de los jornaleros en los campos agrícolas al conseguir resultados favorables en la venta de sus productos en el mercado nacional y global. Otros empresarios de los sectores pecuario, turístico, de la construcción y del comercio, entre otros, han solicitado a su vez mano de obra especializada para cada rama, tomando en cuenta específicas consideraciones del contrato en la agroindustria.

El PTAT se ha consolidado como una política pública binacional. México ha mantenido este programa de movilidad estacional con los canadienses, se caracteriza como uno más de los países que envía mano de obra temporal agrícola, mismo que ha sido crucial desde hace 46 años no únicamente para la viabilidad de las 2 mil 300 granjas en las provincias de esa nación a donde llegan tales trabajadores, sino también para la cadena general de suministro alimentario. Tan sólo en 2019 asistieron 26 mil 399 trabajadores agrícolas, entre ellos 774 mujeres, ${ }^{3}$ quienes desempeñaron sus funciones en invernaderos; viveros o campo 
abierto; cultivos de hortalizas, verduras, legumbres, frutos, flores, tabaco; apicultura; entre otras actividades, con una producción altamente tecnificada.

Para cumplir el envío de mano obra especializada, los operadores responsables de las secretarías involucradas en el PTAT celebran reuniones anuales intergubernamentales de ambos países; se presentan asimismo las asociaciones de granjeros de las tres provincias principales Ontario, Quebec y Columbia Británica; evalúan el programa, analizan problemas e inquietudes de la jornada anterior, plantean soluciones y proyectan la siguiente temporada estacional; deciden cuántos trabajadores, sus actividades, el periodo y la fecha de retorno a su nación; se enlista cada dependencia y reafirman sus compromisos. México inicia el reclutamiento, garantiza el «pedido» con apoyo de la Secretaría del Trabajo y Previsión Social (STPS) ${ }^{4}$ y la Secretaría de Relaciones Exteriores (SRE), ambas responsables del programa. En el Aeropuerto Internacional Benito Juárez de la Ciudad de México la SRE verifica la salida de los mexicanos rumbo a Canadá, incluso prevé tener una reserva de trabajadores en el aeropuerto por si alguno de los citados no concurre, así se asegura el buen servicio eficiente, oportuno y expedito de las secretarías.

Rosa María Vanegas, coautora de este trabajo, gracias a su experiencia de muchos años de investigación sobre el PTAT, mismo que ha incluido largas temporadas de trabajo de campo en granjas canadienses y comunidades de trabajadores agrícolas en diferentes entidades del país, recibió la invitación de la Coordinación General de Empleo de la Dirección de Vinculación de Empleo de la STPS a finales de 2006, para llevar a cabo una evaluación y un análisis de los objetivos del PTAT y el cumplimiento de sus tareas, como parte de la vigilancia gubernamental instrumentada por la Secretaría de la Función Pública (SFP) mediante una Carta Compromiso al Ciudadano, cuyo objetivo es indicar las medidas correctivas para las tareas del PTAT en beneficio de los trabajadores. Después de un extenso escrutinio de la documentación proporcionada por dicha dependencia oficial y de la información recabada durante su investigación, Vanegas determinó que

${ }^{4}$ Informa la STPS que el Programa es una política de empleo que permite la movilidad de manera circular, ordenada y segura. El Sistema Nacional de Empleo de las distintas entidades federativas recluta y selecciona a los candidatos para que acudan a las granjas. La ventaja de Canadá es que los empleadores confían en la selección que hace México, se manda exactamente el perfil laboral del personal que necesita, son mexicanos calificados, especializados en la materia (Secretaría del Trabajo y Previsión Social, 2020a). 
el PTAT es un programa binacional que observa notables avances y mejorías en su funcionamiento administrativo, logístico y laboral. Sin embargo, recae más en el gobierno mexicano la responsabilidad de lograr una articulación de mayor amplitud y eficiencia del programa, ya que el gobierno y los empresarios canadienses tienen al parecer una posición demasiado apegada a la cuestión legal en su aplicación, pero, según su conveniencia, buscan evadir responsabilidades y obligaciones (Vanegas, 2018:172).

Añade que

es una opinión generalizada - entre los usuarios del PTAT, los trabajadores de toda edad y antigüedad de la STPS y los niveles directivos importantes de las oficinas de salud encargadas del seguimiento del estado físico de los trabajadores - la conveniencia de profundizar en la atención de estrategias sociales (sanitarias, familiares, educativas y demás) dentro del programa. Entre éstas debe considerarse una revisión más sensible de los salarios, atención médica de los trabajadores en Canadá, vigilancia de las condiciones y necesidades de las familias de los trabajadores que emigran temporalmente a dicho país, así como profundización en el conocimiento de las condiciones laborales dentro de las unidades productivas canadienses (2018:172-173).

\section{Concluye que}

los campesinos listados en el PTAT son trabajadores controlados, ya que se garantiza el retorno a su país de origen, lo que por otra parte evita que se les otorguen plenamente sus derechos laborales, así como los beneficios en caso de que fueran trabajadores permanentes. Este aspecto del programa es discriminatorio y forma parte de una agenda crítica de organismos canadienses sindicales y de derechos humanos y laborales, respectivamente (2018:174).

Adicionalmente destaca que

en la relación bilateral entre México y Canadá, el Memorándum de Entendimiento sobre trabajadores agrícolas migratorios temporales le permite al gobierno mexicano mantener un férreo control de los trabajadores, desde su contratación hasta su retorno (...). En este sentido, deben revisarse todos los aspectos, condiciones y condicionantes del Memorándum y del contrato, ya que favorecen en mayor medida a 
los empleadores y en consecuencia afectan a los contratados (...). Por último, al no estar considerados como trabajadores formales y al no estar sometido el Memorándum al arbitraje internacional, el cumplimiento de provisiones en su favor queda fuera de toda posible acción legal, sobre todo cuando sus derechos son por una u otra causa violados en el país receptor (2018:174-175).

Hasta hoy las condiciones aludidas no han mejorado ni cambiado, todavía más, permitieron que los trabajadores agrícolas mexicanos que fueron a Canadá en 2020 resultaran afectados con contagio y muerte por la covid-19, según lo mostraremos en el siguiente apartado.

\section{La pandemia de la covid-19 y los trabajadores agrícolas temporales mexicanos migrantes en las provincias de Canadá}

A pesar del «triunfo del PTAT» recientemente se vio en una encrucijada cuando la Organización Mundial de la Salud (OMS) informó que en diciembre de 2019 en la ciudad de Wuhan, provincia de Hubei de la República Popular de China, se presentó un brote epidémico de origen desconocido, lo que causó en los habitantes síntomas diferentes (neumonía, fiebre, tos seca, cansancio, congestión nasal, dolor de cabeza, dolor de garganta, pérdida del gusto o el olfato). Este brote epidémico se propagó de inmediato en Europa y Asia; luego en América, donde rápidamente se extendió en varios países de América Latina; fue entonces que se declaró la pandemia por la enfermedad covid-19.

Ante esta pandemia, los empresarios canadienses entrevieron una crisis global alimentaria, expresaron su preocupación porque los gobiernos cerraran las puertas a los trabajadores extranjeros temporales, pues el sector se vería aún más en graves problemas en la cosecha y pizca de la horticultura, debido a las medidas restrictivas para combatir la propagación del virus al no permitir la llegada de trabajadores a las granjas. Se señaló que el número de trabajadores agrícolas provenientes de México representaba 51.5 por ciento, de Jamaica 19.5 por ciento y de Guatemala 15.2 por ciento, el resto procedía de otros países. El sector empresarial agroindustrial canadiense y los gobiernos de México y Canadá se vieron en la obligación de revisar los protocolos emanados por la OMS, aunado a ello se propusieron adoptar, plantear y tomar en cuenta las recomendaciones de salud. La OMS consideró a la agroindustria como una premisa básica para la producción 
del campo. Así, la industria agrícola y los gobiernos tuvieron que emprender todas las medidas sanitarias expedidas por la OMS para los trabajadores agrícolas migrantes extranjeros tanto a la salida de su nación como al ingreso a Canadá. De no hacerlo podría ser catastrófico dentro de la industria agrícola y en general de las naciones, en cuanto a lo alimentario, lo económico, lo social y lo político. ${ }^{5}$

Al volverse esencial el cultivo de alimentos y una prioridad para la humanidad $y$, en consecuencia, para los gobiernos que exportan e importan mano de obra agrícola, México y Canadá decidieron continuar la operación del PTAT, respetando las medidas sanitarias internacionales. Asimismo, siguiendo los protocolos de salud y protegiendo la seguridad de la vida de los trabajadores agrícolas se comprometieron a reforzar la asistencia médica y salvaguardar los derechos laborales. El Ministerio de Salud de Canadá se responsabilizó de evaluar en cada trabajador su estado físico inmunológico antes de cualquier actividad en el campo, además estarían confinados en la cuarentena de 14 días en las casas-granjas; en esta etapa de aislamiento se les pagarían sus salarios y estarían exentos de erogaciones. La ministra de Agricultura de Canadá, Marie Claude Bibeau, indicó la entrega de mil 500 dólares a cada trabajador, asegurando todas las medidas necesarias en el periodo de aislamiento; enfatizó que la fuerza laboral extranjera es la base vital en la agroindustria de la producción alimentaria en su nación. ${ }^{6}$ Tras estos compromisos se dio nuevamente la salida de los mexicanos hacia Canadá entre el primer y el segundo trimestre de 2020.7 Horacio Duarte Olivares, subsecretario de Empleo y Productividad Laboral de la STPS, informó que para abril se programaron 4 mil 500 connacionales

${ }_{5}^{5}$ Santiago Escobar, representante nacional de la United Food and Commercial Workers Canada (UFCW, por sus siglas en inglés), destacó que la industria agrícola solicita al gobierno federal revisar la prohibición y permitir que los trabajadores agrícolas migrantes ingresen al país, pues de lo contrario podría ser catastrófico para la industria agrícola y la economía canadiense, ya que el suministro de alimentos se podría ver afectado (Chapman, 19 de marzo de 2020).

${ }^{6}$ La ministra de Agricultura de Canadá, Marie Claude Bibeauen, informó en un mensaje vía Twitter: "En regiones del país, los trabajadores temporales extranjeros son esenciales en nuestras granjas, en nuestras plantas de procesamiento de alimentos. Les daremos mil 500 dólares por trabajador extranjero para asegurarnos de que tengan toda la capacidad de implementar todas las medidas necesarias para este periodo de aislamiento" (STPS, 29 de abril de 2020; La Jornada, 20 de abril de 2020; Notimex, 20 de abril de 2020).

${ }^{7}$ El corresponsal Enrique Sánchez del diario Excélsior, de fecha 9 de abril, relata que la Embajada de México en Canadá informó que llegó el primer grupo de 260 mexicanos en el marco del PTAT, luego de que se concretara un entendimiento con las autoridades federales canadienses, gobiernos provinciales y empleadores, para salvaguardar su derecho a la salud y sus derechos laborales, por lo cual gozarán de un salario y estarán exentos de erogaciones que pudieran derivar de este periodo de aislamiento: "Asimismo, y de requerirlo, se ha garantizado su acceso a servicios médicos. La reactivación del Programa en medio de la crisis sanitaria reafirma el compromiso de México con uno de sus principales 
que viajarían a Leamington y a Montreal, provincias de Ontario y Quebec, respectivamente. El 15 de abril salieron mil 500 a los que se sumarían otros 2 mil 700 durante el resto del mes. Se consideró que al final del segundo trimestre se alcanzaría un total de 8 mil 700 trabajadores agrícolas (STPS, 29 de abril 2020).

Con todo, la salida de los jornaleros del PTAT una vez más se interrumpió cuando la SRE y la STPS se enteraron de que algunos mexicanos se habían contagiado de la covid-19. Los medios de difusión y organizaciones sociales ${ }^{8}$ dieron constancia de lo que estaba sucediendo en las granjas, ofrecieron su apoyo a los jornaleros temporales por los acontecimientos suscitados; de igual modo, preocupados cuando vieron que las medidas de seguridad sanitaria no se efectuaban como debía ser, realizaron varias llamadas a los consulados mexicanos. Nicolas Haddad, de la ICI Windsor, entrevistó a Syed Hussan, director de la Alianza de Trabajadores Migrantes para el Cambio (MWAC), quien dio a conocer, el 8 de junio, que en la granja Scotlynn Sweetpac, ubicada en el condado Norfolk, había 164 trabajadores contagiados del virus y dos más habían fallecido. Las condiciones en que se encontraron a los jornaleros no eran las óptimas: carecían de alimentos, agua caliente, faltaba equipo de protección personal, existían malos tratos, exceso laboral y discriminación, esto obligó a los funcionarios consulares mexicanos a revisar lo que estaba sucediendo en las provincias.

La Embajada de México en Ottawa corroboró el contagio de 302 trabajadores agrícolas, dos decesos ${ }^{9}$ y dos más en situación delicada. El gobierno de México decidió suspender de inmediato temporalmente el arribo de trabajadores en Canadá y la sede diplomática mexicana se dio a la tarea de investigar lo sucedido e instó a los representantes canadienses del PTAT que aclararan el por qué del contagio y la muerte de los connacionales, si se habían aplicado los protocolos

aliados y es una de las manifestaciones más claras del principio de solidaridad que ha guiado las acciones de nuestro país en esta crisis mundial» (Sánchez, 9 de abril de 2020).

${ }^{8}$ La Alianza de Trabajadores Migrantes para el Cambio, una red integrada por una amplia gama de organizaciones sociales, reveló en un informe que los trabajadores temporales que llegan a Canadá en su mayoría no tienen acceso a equipos de protección en el trabajo. También denunció las condiciones de hacinamiento en las que vivían las cuales no permitían el distanciamiento físico obligatorio para impedir el contagio y la propagación del coronavirus (Sánchez, 9 de abril de 2020).

${ }^{9}$ Oficialmente se reportó la muerte de dos trabajadores agrícolas mexicanos tras haberse infectado de covid-19. Se trata de Bonifacio Eugenio Romero de 31 años, quien falleció el 30 de mayo, tan sólo 30 minutos después de haber ingresado al hospital; y de Rogelio Muñoz Santos de 24 años, el 5 de junio, quien tras varios días de sufrir por las consecuencias del virus falleció en Leamington, Ontario. Él era de la comunidad de Monte Alegre, municipio de Tecpactan, Chiapas, y llegó a Toronto en febrero como turista (La Jornada, 16 de junio de 2020). 
de salud y seguridad en la protección de los trabajadores, y hasta que no se esclareciera lo anterior, el gobierno mexicano detendría el proceso del PTAT. Por su parte, la Comisión Nacional de Derechos Humanos (CNDH) de México resaltó el inicio de la investigación de oficio por la muerte de los trabajadores agrícolas mexicanos en granjas de la provincia de Ontario tras haberse infectado por el SARS-COV-2.

Óscar Mora, portavoz de la legación diplomática mexicana en Canadá, indicó que estuvo revisando reglas protocolarias y políticas sanitarias antes de continuar con la llegada de trabajadores agrícolas a ese país. Asimismo, remarcó que el embajador de México en Canadá, Juan José Gómez Camacho, dio a conocer que existían alrededor de 300 mexicanos contagiados por el coronavirus y la pérdida de dos vidas en Windsor, Ontario (Gilmore, 2020; Chapman, 16 de junio de 2020). El embajador estuvo en comunicación con los representantes del gobierno de dicho país, a quienes solicitó la explicación y razones de lo acaecido, mientras tanto suspendió la salida de 5 mil trabajadores que ya estaban listos para presentarse en las granjas. A fin de poner en marcha nuevamente al PTAT debía tener la certeza y el compromiso del gobierno canadiense de no repetirse más brotes del coronavirus a los compatriotas. Propuso adoptar medidas adicionales en materia de salud, aparte de las ya establecidas por la OMS:

Primero, fortalecer la supervisión por parte de las autoridades canadienses a las condiciones físicas y de funcionamiento de las granjas.

Segundo, sancionar a los granjeros que no cumplan los acuerdos y contratos, realizar supervisión a viviendas (alojamiento adecuado, no al hacinamiento) y áreas de trabajo.

Tercero, establecer teléfonos al servicio de los trabajadores para que reporten cualquier anomalía.

Cuarto, se instituyó un grupo de tarea binacional, conformado del lado canadiense por los ministerios de Agricultura, Salud, Migración y Aduanas; por parte de México la Embajada, la STPS y los consulados.

Quinto, en caso de ser víctimas del contagio, la atención a la salud será igual a los trabajadores canadienses, garantizando derechos laborales y humanos.

Paralelamente, se estableció un compromiso a largo plazo entre ambas partes con la finalidad de revisar el contrato laboral del programa: examinar, replantear, fortalecer, modernizar el acuerdo, indicar qué ha evolucionado con parches y qué debe empezar a trabajarse desde cero. El embajador Gómez Camacho, igualmente, planteó revisar el hacinamiento en las viviendas, las cuales no eran nada favorables 
a los trabajadores, hecho que propició el contagio de la covid-19, insistió en que estos escenarios también se ven en las granjas familiares. El gobierno canadiense dispuso mejorar los espacios de descanso; con relación al pago por hora trabajada, el embajador planteó cómo deberían ser los domingos, dado que los trabajadores agrícolas se presentan a laborar toda la semana sin tener descanso un solo día, en tal caso se les debe pagar igual que a los nacionales.

El 15 de junio el presidente de México, Andrés Manuel López Obrador, y el primer ministro de Canadá, Justin Trudeau, hablaron por teléfono, comentaron la relación económica bilateral, el tratado comercial T-MEC que inició el 1 de julio, y la situación de contagio de cientos de mexicanos, así como los fallecidos. El primer ministro Trudeau lamentó el deceso de los jornaleros en la provincia de Ontario a consecuencia de la covid-19, hizo hincapié en que se haría la investigación y el seguimiento del brote en las granjas de su país, ${ }^{10}$ sugirió otorgar la ciudadanía canadiense a trabajadores agrícolas latinoamericanos; por su parte, el gobierno de Ontario se comprometió a realizar 8 mil pruebas entre los agricultores temporales. ${ }^{11}$

Siguiendo los acontecimientos y los planteamientos de los responsables del PTAT, el primer ministro Justin Trudeau repitió al embajador de México en Canadá, Gómez Camacho, la propuesta de otorgar la residencia permanente a trabajadores que son contratados en la agroindustria, reconoció que la producción agrícola en su natal residencia depende de los trabajadores extranjeros temporales y literalmente mencionó: «Siempre deberíamos aprovechar momentos de crisis para reflexionar sobre cambios en el sistema y hacerlo mejor para los canadienses, pero también para la gente que viene aquí y garantiza que tengamos alimentos» (Milenio, 21 de marzo de 2020).12

${ }^{10}$ Durante su conferencia de prensa diaria, Trudeau reconoció la gravedad de la situación y explicó que ha abordado con el presidente de México, Andrés Manuel López Obrador, la problemática de los trabajadores agrícolas extranjeros: «Hablé con el presidente López Obrador hace sólo dos días y hablamos de este tema. Le expresé mis simpatías y condolencias con las familias de los trabajadores mexicanos que murieron en Canadá. Como país, estamos preocupados con lo que ha pasado y vamos a asegurarnos de que sabemos qué ha sucedido y que mantenemos a todos los trabajadores seguros» (Milenio, 21 de marzo de 2020).

${ }^{11}$ El primer ministro de Canadá, Justin Trudeau, se mostró dispuesto a conceder la nacionalidad canadiense a miles de trabajadores temporales, en su mayoría latinoamericanos y caribeños, que acuden cada año al país a laborar en explotaciones agrícolas (El Mundo, 16 de junio de 2020; El Popular, 16 de junio de 2020).

${ }^{12} \mathrm{El}$ anuncio del primer ministro de conceder la nacionalidad canadiense llegó después de que dos trabajadores agrícolas de México murieron en ese país tras contraer covid-19 y cientos más resultaran infectados: «Sabemos que hay muchos problemas con las condiciones de vida, que los trabajadores 
En este momento, la propia comunidad, los patrones, las autoridades responsables del programa, las asociaciones civiles, los sindicatos y demás personalidades canadienses, reconocen y les preocupa la situación del trabajador agrícola, quien desempeña cabalmente sus labores, no sólo para los canadienses, sino también para el gobierno mexicano, en especial aquellos que se vinculan con el PTAT. Es lamentable en el caso de ambas partes que hasta ahora que se presentó la pandemia SARS-CoV-2, se den cuenta de las anomalías suscitadas con los trabajadores. Desde hace décadas saben de las violaciones que existen en las granjas, del hacinamiento en que se encuentran los trabajadores, de la falta de atención de los consulados mexicanos en verificar que se cumpla mínimamente lo establecido en el contrato, de que en las estancias se deben tener los servicios básicos - todo tipo de utensilios en la cocina, agua como base esencial para beber y lavar-y otras actividades que se necesiten. La patronal debe pagar horas extras en días de descanso y festivos, respetar los días de descanso, sancionar a los patrones que no cumplan con su responsabilidad; estos son algunos puntos del contrato que con frecuencia no se realizan.

Las propuestas que efectúan tanto el primer ministro, Justin Trudeau, de otorgar el derecho de ciudadanía a los agricultores, poner más énfasis al cuidado para no permitir el hacinamiento en las estancias, castigar a los patrones que no ejecuten las reglas establecidas por la covid-19; así como el embajador de México en Canadá, Gómez Camacho, de revisar el contrato integralmente porque ya no cumple las expectativas actuales del PTAT, son demandas que los trabajadores agrícolas temporales han venido haciendo desde hace varias décadas. Ante la continuidad de la pandemia, las autoridades de ambas naciones se aseguraron de que los trabajadores afectados por el coronavirus pudieran retornar a sus comunidades, les dieron el apoyo necesario, en particular a las familias que perdieron a sus seres queridos en Canadá.

En una conferencia realizada el 14 de octubre, en el marco de las Conferencias sobre Programas del Bienestar, Luisa María Alcalde Luján, secretaria del STPS, dedicó la sesión al PTAT (STPS, 14 de octubre de 2020). La acompañaron Marath Bolaños, subsecretario del Servicio Nacional de Empleo, y Donaciano Domínguez, subcoordinador general, del cual forma parte el PTAT. Donaciano Domínguez durante su intervención planteó lo siguiente:

están vinculados con compañías concretas y problemas con estándares laborales. Podemos también mirar formas de conseguir la ciudadanía, que puede dar a los trabajadores más derechos» (Milenio, 21 de marzo de 2020). 
¿Qué sucede con los trabajadores al ir a Canadá?, que contribuyen de manera directa en el sector primario y que en esta pandemia, y subrayamos en esta pandemia, han sido identificados como trabajadores esenciales al contribuir en el sector primario y ser garantes de la seguridad alimentaria en nuestro socio y aliado que es Canadá.

La Secretaría de Salud nos apoya en la emisión de exámenes médicos para los trabajadores y en esta temporada de pandemia ha sido fundamental en el proceso de información y orientación para la aplicación de las medidas sanitarias necesarias para que se dé seguro el traslado de los trabajadores.

A nivel de números, el programa (...) arranca en 1974 con el envío de 203 trabajadores; vemos una línea ascendente totalmente. Sin embargo, tenemos en 2020 de manera muy explícita el fenómeno de la pandemia, que impacta de manera puntual el envío de trabajadores en casi 4 mil. Quiero subrayar acá que la instrucción del presidente en el mes de marzo, cuando por ahí del 18 cierran las fronteras en Canadá y se abren hasta el 9 de abril. Hay una instrucción puntual de no suspender la operación del programa, promover e impulsar la atención de trabajadores, partiendo del perfil que ya señalamos antes, son trabajadores de los más necesitados en el país que debían salir en busca de una oportunidad laboral, en ese sentido el Servicio Nacional de Empleo y la Secretaría del Trabajo no dejan de operar, reestructuran todos sus procesos, aquellos procesos que eran presenciales, para poder recibir a los trabajadores ahora en el aeropuerto. Un proceso que hacíamos antes en las oficinas de la Secretaría del Trabajo, que ahora los espacios no nos permitían tener ningún tipo de aglomeración por el tema de la sana distancia. Lo trasladamos al aeropuerto donde tenemos todas las facilidades para poder atender a los trabajadores y continuamos con la operación.

Hay definitivamente una caída en la operación del programa, pero hay una meta totalmente superada en las expectativas que tenía la Secretaría del Trabajo sobre el volumen de trabajadores que íbamos a enviar. Cabe señalar que los trabajadores estaban listos para salir; son los empleadores quienes al ver impactado sus procesos productivos también, en la comercialización de productos, terminan suspendiendo el pedido de algunos trabajadores.

A nivel de provincias estamos trabajando fundamentalmente en Ontario, Columbia Británica y Quebec acá destaca ya lo señalado, la operación continua que tuvo la Secretaría del Trabajo del Servicio Nacional de Empleo, pero no fue menor el trabajo que realizó la Secretaría de Relaciones Exteriores en Canadá; donde las áreas de protección consular, los consulados, nuestra Embajada de México en Canadá, y la Dirección General de Protección a Mexicanos en el Exterior, estuvieron 
pendientes acompañando en todo momento a los trabajadores, durante el proceso de inicio de labores que cabe señalar, se instrumenta un periodo de cuarentena en Canadá de 14 días; donde los trabajadores reciben un pago semanal por el equivalente a 30 horas de trabajo; hasta en tanto se reincorporan en el proceso (2020:4-10).

Al término de su intervención, dos reporteros participan con preguntas. Juan Carlos Machorro de AM de Querétaro: «iQué tanto se afectó la inscripción o el viaje de mexicanos y en esta perspectiva, creen que se va a seguir reflejando en el 2021? Gracias» (2020:12). Donaciano Domínguez responde:

La pandemia, lo dijimos, nos impactó en más de cuatro mil trabajadores. No así en el número de empleadores, de hecho tenemos alrededor de 120 empresas nuevas con empleadores independientes; que se van sumando al programa y la expectativa, aun cuando ya nos han anunciado que la cuarentena para Canadá se amplía hasta el mes de junio, está probado que aplicando las medidas de sanidad en los términos que han planteado las autoridades responsables, podemos salir adelante y recuperar, al menos en el próximo año, estos 4 mil trabajadores que no salieron en la presente temporada (2020:12).

Óscar Sosa (no se aclara de qué medio es reportero) pregunta: « ¿Van a cambiar los paradigmas? ¿Han tenido pláticas con el gobierno canadiense y con los empleadores? ¿Van a hacer nuevos procesos para la gente que quiera poder establecer un trabajo allá? Si nos puede informar. Muchas gracias» (2020:13). Donaciano Domínguez responde:

Comentarle del caso particular covid, Programa de Trabajadores Agrícolas Temporales México-Canadá, estamos platicando, de manera muy cercana, con el gobierno de Canadá, con el Gobierno Federal y las autoridades provinciales desde la Secretaría del Trabajo, en el Servicio Nacional de Empleo y desde nuestras representaciones consulares, la Embajada en Canadá, para afrontar la temporada 2021. En este proceso, que ya nos han avisado que se amplía el periodo de cuarentena, nos obliga en México a cambiar y transitar de lo que era un trámite o una solicitud de permiso de trabajo en papel, a tener que hacer los procesos ahora en línea.

Esto significa que nos pone el gran reto de enseñarle a un trabajador a entender formatos. Y no lo tiene que hacer él, lo hace el personal del Servicio Nacional de Empleo, lo hace el personal de la secretaría para poder traducir el formato de permiso 
de trabajo y poder salir. O sea, se está omitiendo la aplicación de exámenes biométricos en México y se están realizando para los trabajadores nuevos al cruzar la frontera. Son algunas de las acciones que están realizando. La cuarentena permanecerá y, para autorizar que vaya un trabajador mexicano a Canadá, las empresas tienen que cumplir con una serie de medidas sanitarias y de supervisión de las condiciones de vivienda para que se pueda garantizar que existen condiciones sanitarias idóneas para el desempeño de los trabajadores. Y, evidentemente, el acompañamiento de las autoridades de salud en Canadá para garantizar la atención en todo momento de los trabajadores en Canadá (2020:13-14).

Al final interviene la secretaria de la STPS, Luisa María Alcalde Luján:

Nada más para reforzar esta idea, en el gobierno canadiense, se han venido, igual que en otros sectores; pero se tiene un protocolo, igual que en nuestro país, de cuáles son las condiciones que tienen que tener los centros de trabajo para poder trabajar en forma segura. Y también se hacen verificaciones para que esto suceda y eso nos da certeza y le da certeza a los trabajadores, a las trabajadoras que se van para allá, que llegarán a un lugar que cumpla con los protocolos y en donde pueden estar seguros. Obviamente, pues esta... digamos, nadie está exento de contagios; pero siempre se les da un seguimiento puntual. Entonces, eso seguirá hasta en tanto pues no se cuente con una vacuna (2020:14).

\section{Conclusiones}

La crisis sanitaria global provocada por la pandemia de la covid-19 profundizó la crisis económica estructural de 2008, misma que no ha logrado salir avante a pesar de diversos mecanismos que el capital transnacional ha instrumentado en la última década, entre ellos, la renegociación del Tratado de Libre Comercio de América del Norte (TLCAN), que dio paso al Tratado entre México, Estados Unidos y Canadá (T-MEC), el cual entró en vigor el 1 de julio de 2020.

A escasas semanas de haberse suspendido las actividades laborales en muchos sectores económicos de los tres países, los gobiernos de Estados Unidos y Canadá, junto con los empresarios de los tres países, comenzaron a presionar al gobierno mexicano para que se reanudaran distintas actividades que no se habían considerado sustantivas. Aunque el gobierno mexicano había planteado que se estaba 
entrando en la curva ascendente de la pandemia, levantó la contingencia con el objeto de que los trabajadores pudieran regresar a laborar, lo que provocó que muchos se contagiaran y que incrementara el número de fallecidos. En algunos casos, como en las maquiladoras de la frontera norte, no se permitió que los trabajadores se quedaran en casa, en otros, las labores se suspendieron determinados días, lo que significó que muchos trabajadores y trabajadoras se contagiaran y un número importante falleciera.

Eso fue lo que sucedió con los trabajadores agrícolas temporales que viajaron a Canadá. Las condiciones en que llegaron fueron las mismas que hace décadas, a pesar de que han luchado para que cambien. Los Programas de Trabajadores Temporales (PTT) existentes desde la época del Programa Bracero en México, hasta el PTAT con Canadá y los H-2A y H-2B dirigidos por el Departamento del Trabajo de los Estados Unidos, no tienen los instrumentos legales para hacer cumplir las legislaciones correspondientes en los casos de violaciones laborales y de otros derechos humanos, las cuales son constantes (Binford et al., 2004; Sandoval y Vanegas, 2001; Vanegas, 2018). Públicamente, el PTAT con Canadá ha sido difundido por las autoridades mexicanas como un gran éxito, y como el modelo a seguir en el momento en que se negocie un nuevo contrato de trabajadores temporales entre México y Estados Unidos. El lado oscuro del programa es que los trabajadores reciben bajos salarios, tienen largos jornales, una limitada protección contra abusos y un contrato que favorece al granjero canadiense, ello hace de los mexicanos una mano de obra cautiva, aprovechada por los granjeros en sus esfuerzos por adaptarse al libre mercado y la competencia global.

Los acuerdos entre los gobiernos de México y Canadá para la protección y seguridad de los trabajadores agrícolas temporales son paliatorios y coyunturales. La protección y seguridad quedarían a cargo de los ministerios canadienses de salud, agricultura, migración y empleo; y de la STPS y la SRE que serían los responsables de intervenir y solucionar con prontitud cualquier problema o denuncia, o si se presentara de nuevo cierto brote de covid-19 deberían atender rápidamente el lugar donde se hospedan los jornaleros..$^{13}$ Lo que se busca es que no se detenga

${ }^{13}$ Una vez que se garantizaron las condiciones sanitarias en las granjas canadienses para evitar riesgos de posibles contagios de covid-19 entre los trabajadores agrícolas, los gobiernos de México y Canadá saldaron sus diferendos y alcanzaron un acuerdo para reactivar el PTAT, que estuvo varios días en una «pausa temporal»: «Para atender de manera oportuna los retos identificados en el contexto de la pandemia, ambos países establecieron un nuevo grupo de contacto, que está integrado por los ministerios de Salud, Migración, Agricultura y Empleo de Canadá, así como la STPS y SRE por parte de México. El objetivo de este grupo será identificar riesgos, atender denuncias y facilitar la intervención inmediata 
el trabajo agrícola, pues la agroindustria alimentaria es prioritaria a los intereses políticos y económicos de Canadá, y el gobierno mexicano acepta la continuidad del programa al seguir enviando la fuerza laboral agrícola necesaria.

Desde hace más de 50 años que inició el programa de trabajadores extranjeros agrícolas temporales con el Caribe y posteriormente México, Guatemala y El Salvador, entre otros. Como trabajadores de primera línea han hecho significativas contribuciones en la atención alimentaria y en la economía del país, por años les han retenido de su salario contribuciones para el fondo de protección social, subsidiando el fondo del seguro de desempleo. Los reconocimientos que hacen las autoridades canadienses hacia los jornaleros podrían demostrarlos al serles restituidas sus aportaciones al fondo de protección social. Las propuestas de formalizar la residencia permanente, recibir los beneficios de las prestaciones sociales-laborales del trabajador nacional y otras apuntan a la búsqueda de la consolidación del mercado laboral subregional, puesto que esta crisis mostró la vulnerabilidad del PTAT por la precariedad de las condiciones de trabajo y de salud que muestran los trabajadores agrícolas temporales en las granjas canadienses.

\section{Referencias}

Acuña, R. (2007). Corridors of migration. The odissey of Mexican laborers.1600-1933. Tucson: The University of Arizona Press.

Alanis, F. (1999). El primer programa bracero y el gobierno de México 1917-1918. San Luis Potosí: El Colegio de San Luis.

Asamblea General de las Naciones Unidas (2018). Documento final de la Conferencia Intergubernamental encargada de aprobar el Pacto Mundial para la Migración Segura, Ordenada y

a favor de los trabajadores agrícolas mexicanos, mediante las siguientes acciones: apoyar el trabajo del gobierno de México para detectar de manera oportuna las granjas con brotes o alto riesgo de brotes; que la administración canadiense, en colaboración con agencias de salud locales, garantizará el adecuado acceso a la salud, inspecciones y atención médica oportuna para los trabajadores. También, de manera proactiva, incrementarán las capacidades de Service Canada para revisar actos de incumplimiento y se asignará a un contacto para trabajar con los consulados mexicanos sobre inconsistencias detectadas, trabajarán con provincias y territorios sobre las responsabilidades que les corresponden, así como continuar informando a los empleadores sobre sus obligaciones bajo el PTAT, particularmente en lo concerniente a la prevención del contagio de la covid-19» (La Jornada, 21 de junio de 2020). Sin embargo, a principios de octubre de 2020 una nueva eclosión de la covid-19 surgió entre los trabajadores agrícolas temporales en Kingsville, Ontario, donde 17 de éstos se contagiaron del virus (CBC News, 10 de octubre de 2020). 
Regular. Marrakech, 10 y 11 de diciembre. Recuperado de http://undocs.org/es/A/ CONF.231/3

Binford, L., Carrasco, G., Arana, S. y Santillana, S. (2004). Rumbo a Canadá. La migración canadiense de trabajadores agrícolas tlaxcaltecas. México: Taller Abierto/Sociedad Cooperativa de Producción, S.C.L.

Casarrubias, D. (2007). «El problema del éxodo de braceros en México y sus consecuencias». En Durán, J. (coord.), Braceros. Las miradas mexicana y estadounidense. Antología (1945-1964) (pp. 343-405). Ciudad de México: Senado de la República, LX Legislatura/Universidad Autónoma de Zacatecas/Miguel Ángel Porrúa.

CBC News (10 de octubre de 2020). "Ontario: nouvelle éclosion de COVID-19 chez les travailleurs agricoles migrants». Recuperado de https://ici.radio-canada.ca/ nouvelle/1740287/eclosion-travailleurs-migrants

Chapman, L. (19 de marzo de 2020). "Cerrar puertas a trabajadores extranjeros sería catastrófico para Canadá». Radio Canadá Internacional en Español (RCI). Recuperado de https://www.rcinet.ca/es/

Chapman, L. (16 de junio de 2020). «México prohíbe a trabajadores temporales venir a Canadá. Radio Canadá Internacional en Español (RCI). Recuperado de https://www. rcinet.ca/es/

Cohen, D. (2011). Braceros. Migrant citizens and transnational subjects in the postwar United States and Mexico. Chapell Hill: The University of North Carolina Press.

Driscoll, B. (1996). Me voy pa' Pensilvania por no andar en la vagancia. Los ferrocarrileros mexicanos en Estados Unidos durante la Segunda Guerra Mundial. Ciudad de México: Consejo Nacional para la Cultura y las Artes/Universidad Nacional Autónoma de México.

Durán, J. (2007). «¿Un acuerdo bilateral o un convenio obrero patronal?» En Durán, J. (coord.), Braceros. Las miradas mexicana y estadounidense. Antología (1945-1964) (pp. 11-30). Ciudad de México: Senado de la República, LX Legislatura/Universidad Autónoma de Zacatecas/Miguel Ángel Porrúa.

El Mundo (16 junio de 2020). «Trudeau, dispuesto a ofrecer la nacionalidad a trabajadores temporales latinos». El Mundo.

El Popular (16 de junio de 2020). "Concederían nacionalidad canadiense a inmigrantes mexicanos». El Popular.

Sánchez, E. (9 de abril de 2020). "Trabajadores agrícolas mexicanos llegan a Canadá». Excélsior.

Gilmore, R. (22 de junio de 2020). «Mexico won't send workers to Canadian farms that ignore COVID-19 rules: ambassador». CTV News. Recuperado de https://www. 
ctvnews.ca/health/coronavirus/mexico-won-t-send-workers-to-canadian-farmsthat-ignore-covid-19-rules-ambassador-1.4995354

ICI.Radio-Canada.ca (8 de junio de 2020). "Covid 19: un rapport accablant sur situation des trabailleurs agricoles étrangers». Recuperado de https://ici.radio-canada.ca/nouvelle /1710023/rapport-travailleurs-agricoles-saisonniers-etrangers-migrants-covid

La Jornada (10 de abril de 2020). "Contagiados, 19 mexicanos en granja de Columbia Británica». La Jornada.

La Jornada (20 de abril de 2020). "A Canadá, 4 mil 500 jornaleros mexicanos». La Jornada.

La Jornada (10 de junio de 2020). «Piden que cónsules atiendan a trabajadores migrantes en Canadá». La Jornada.

La Jornada (14 de junio de 2020). «Abre CNDH carpeta por muerte de dos jornaleros en Ontario». La Jornada.

La Jornada (16 de junio de 2020). «México no enviará trabajadores a granjas de Canadá con brotes de Covid». La Jornada.

La Jornada (21 de junio de 2020). "Reactivarán programa temporal para trabajadores agrícolas». Recuperado de https://jornada.com.mx/ultimas/sociedad/2020 /06/21/ reativaran-programa-temporal-para-trabajadores-agricolas-3158.html

La Jornada (23 de junio de 2020). «Vigilará Canadá granjas agrícolas ante contagio». La Jornada.

Kolko, J. (1988). Restructuring the world economy. New York: Pantheon Books.

Machuca, J.A. (1990). Internacionalización de la fuerza de trabajo y acumulación de capital: México-Estados Unidos (1970-1980). México: Instituto Nacional de Antropología e Historia.

Marx, K. (1990). El capital (tomo I). México: Siglo XXI.

Milenio (21 de marzo de 2020). "Trudeau, dispuesto a otorgar nacionalidad a trabajadores latinos». Recuperado de www.milenio.com>internacional/canada-dara-naciona lidad-trabajadores-agricolas-extranjeros

Noticias de Querétaro (20 de abril de 2020). "Aumenta salida de mexicanos con jornaleros a Canadá». Noticias de Querétaro.

Notimex (20 de abril de 2020). «Trabajadores mexicanos a Canadá». Notimex.

Overbeek, H. (2002). "Neoliberalism and the regulation of global labor mobility», Annals of the American Academy of Political and Social Science, 581, pp. 74-90.

Potts, L. (1990). The world labour market. A history of migration. Londres y Nueva Jersey: Zed Books.

Peña, A.A. (2013). Migración internacional y superexplotación del trabajo. México: Itaca. 
Robinson, W. (2013). Una teoría sobre el capitalismo global. Producción, clase y estado en un mundo transnacional. México: Siglo XXI.

Rodriguez, R.M. (2010). Migrants for export. How Philippine state brokers labor to the world. Minneapolis y Londres: University of Minnesota Press.

Sandoval, J.M. (2019). «Los migrantes de México y Centroamérica en la conformación del mercado laboral regional de América del Norte (décadas de 1980 a 2010)», Antrophos (250), pp. 139-154.

Sandoval, J.M. (2015). «El Programa Bracero, los Programas de Trabajadores Temporales (PTT) y el mercado mundial de fuerza laboral». En Grijalva, A. y Arriaga, R. (coords.), Tras los pasos de los braceros. Entre la teoría y la realidad (pp. 77-138). México: Instituto de Investigaciones Sociales-Universidad de Baja California/Juan Pablos Editores.

Sandoval, J.M. (2013). "El Programa Bracero y las políticas de trabajadores migratorios temporales para un mercado laboral regional de América del Norte». ISTOR, XIII(52), pp. 55-90.

Sandoval, J.M. y Vanegas, R.M. (2001). «Migración laboral agrícola temporal mexicana a Estados Unidos y Canadá: viejos-nuevos problemas». Dimensión Antropológica, 8(21), pp. 113-172.

Sassen, S. (1988) The mobility of labor and capital. A study in international investment and labor flow. Cambridge y Nueva York: Cambridge University Press.

Secretaría del Trabajo y Previsión Social (STPS) (29 de abril de 2020). «Protege STPS empleos de trabajadores agrícolas en Canadá ante el Covid-19». Boletín de Prensa, 037/2020.

Secretaría del Trabajo y Previsión Social (STPS) (14 de octubre de 2020). «Conferencias sobre Programas del Bienestar: Programa de Trabajadores Agrícolas Temporales entre México y Canadá». Feria Nacional del Empleo. Recuperado de www.gob.mx/stps/es/ articulos/feria-nacional-del-empleo-conferencias-sobre-programas-del-bienestar ?idiom $=$ es

Trigueros, P. (2004). «Participación de los migrantes mexicanos en la agricultura estadounidense». En Levine, E. (coord.), Inserción laboral de migrantes laborales y latinos en Estados Unidos (pp. 11-31). México: Universidad Nacional Autónoma de México.

Vanegas, R.M. (2018). 4 décadas del Programa de Trabajadores Agrícolas Temporales MéxicoCanadá: 1974-2014. México: Instituto Nacional en Antropología e Historia.

Vanegas, R.M. (2008a). «El proceso migratorio temporal en Canadá». Ponencia presentada en el Seminario Internacional The remains, Legacy and Transcendence of NAFTA, del 5 al 7 marzo. 
Vanegas, R.M. (2008b). "Los Memorándum de Entendimiento de México con Canadá y España». Ponencia presentada en el Primer Congreso Latinoamericano sobre Migración Internacional Voces del Sur. Toluca, Estado de México, 12-14 de noviembre.

Vargas, G. (2007). «El problema del bracero mexicano». En Durán, J. (coord.), Braceros. Las miradas mexicana y estadounidense. Antología (1945-1964) (pp. 407-459). Ciudad de México: Senado de la República, LX Legislatura/Universidad Autónoma de Zacatecas/Miguel Ángel Porrúa. 